\title{
Early Molecular Replication of Human Immunodeficiency Virus Type 1 in Cultured-Blood-derived T Helper Dendritic Cells
}

\author{
Erik Langhoff, ${ }^{\star}$ Karl H. Kalland, ${ }^{\star}$ and William A. Haseltine ${ }^{\star}$ \\ *Division of Human Retrovirology, Dana-Farber Cancer Institute, Boston, Massachusetts 02115, \\ and ${ }^{\ddagger}$ The Center for Virology, HIB, University of Bergen, N-5020 Bergen, Norway
}

\begin{abstract}
The rate and efficiency of key steps in the life cycle of the human immunodeficiency virus type 1 was examined in three primary cell types, $T$ cells, monocytes, and $T$ helper dendritic cells using the same quantity of virus involved and same cell number. The results show that viral DNA synthesis proceeds much more rapidly and efficiently in primary $T$ helper dendritic cell populations than in primary $T$ cell and monocyte populations. The increased rate of virus DNA synthesis is attributable either to an increase in the efficiency and the rate of uptake of the virus particles by the $T$ helper dendritic cells, as compared with that in other cell types, or to an increased efficiency and rate of viral DNA synthesis in the T helper dendritic cells. In the subsequent phase of viral expression the appearance of spliced viral mRNA products also occur more rapidly in cultures of primary-blood-derived $\mathrm{T}$ helper dendritic cells than is the case in primary $T$ cells and monocytes. The increased efficiency of the early steps of HIV-1 replication in primaryblood-derived $\mathrm{T}$ helper dendritic cells than in other blood-derived mononuclear cells raises the possibility that these cells play a central role in HIV-1 infection and pathogenesis. ( $J$. Clin. Invest. 1993. 91:2721-2726.) Key words: polymerase chain reaction • reverse transcription • integration • monocytes • T cells
\end{abstract}

\section{Introduction}

The human immunodeficiency virus type 1 (HIV-1) has been shown to infect several different cells of hematopoietic origin, including $\mathrm{CD}^{+} \mathrm{T}$ cells, monocytes, macrophages, and circulating $\mathrm{T}$ helper dendritic cells. The cells most susceptible to infection by low titers of virus in culture are blood-derived $\mathrm{T}$ helper dendritic cells. These cells can be infected by low concentrations of both primary and laboratory strains of HIV-1 (1). Once infected, the $T$ helper dendritic cells produce significantly more infectious virus per cell than do infected cultures of primary $\mathrm{CD} 4^{+} \mathrm{T}$ cells and monocytes and macrophages (1). The high level of virus produced by purified populations of

Address reprint requests to Erik Langhoff, M.D., Division of Human Retrovirology, Dana-Farber Cancer Institute, 44 Binney Street, Boston, MA 02115.

Received for publication 2 April 1992 and in revised form 26 January 1993.

J. Clin. Invest.

(C) The American Society for Clinical Investigation, Inc. $0021-9738 / 93 / 06 / 2721 / 06 \$ 2.00$

Volume 91, June 1993, 2721-2726 primary dendritic cells is remarkable as these cells are terminally differentiated and do not proliferate in culture. Several studies show that the fraction of blood-derived mononuclear cells containing $T$ helper dendritic cells purified from the blood of HIV-1 infected patients contain significant amounts of HIV1 viral DNA (2-4) although contamination from other cell types is a possibility (5).

The experiments presented here address the question of the relative speed and efficiency of early steps in the virus life cycle, synthesis of virus DNA in the newly infected cells, and production of spliced viral messenger RNA.

\section{Methods}

Isolation and infection of primary leukocytes. Purified-blood-derived $T$ helper dendritic cells were isolated as described $(1,6,7)$. Briefly, unfractionated PBMCs from blood donor buffy coats were depleted for monocytes and $T$ cells by density separation on Percoll gradients and by rosetting with neuraminidase-treated sheep erythrocytes. The remaining leukocyte fraction was enriched for dendritic cells by a second reflotation on Percoll gradients after $2 \mathrm{~d}$ of culture, and further depleted of contaminating monocytes by Fc panning on IgG-coated dishes and of residual lymphocytes by panning with monoclonal antibody to CD45RA $(1,7)$. This procedure yields a population of cells that are estimated to be at least $75 \% \pm 7 \%$ pure as previously published (1) and comparable with other reports (7). They are $\mathrm{CD}^{-}, \mathrm{CD}^{-} 4^{-}$, $\mathrm{CD}^{-} 0^{-}$, and strongly $\mathrm{DR}^{+}$as determined by $\mathrm{FACS}^{\circledR}$ analysis (not shown ) and by immunoperoxidase staining of cytocentrifuged preparation of dendritic cells (1). T cells (high density, E rosette positive cells) and monocytes (low density, $E$ rosette negative cells) were isolated as described $(1,6)$. Briefly, $T$ cells are high density cells separated by Percoll gradient centrifugation (6) and further purified by rosetting with neuraminidase-treated sheep red blood cells (SRBC) (6). This procedure yields $>96 \%$ pure $T$ cells as determined by immunostaining (1). Monocytes are low density cells from Percoll gradient centrifugation depleted of contaminating $T$ cells by rosetting with neuraminidase-treated SRBC (1). During the total isolation procedure all leukocyte isolates were cultured for the same time period in growth medium of RPMI 1640 with $10 \%$ FCS and antibiotics without exogenous stimulation. Before virus inoculation all primary cells were plated at 200,000 cells per well ( 24 well plates, Nunc, Roskilde, Denmark) and exposed overnight to growth medium with $20 \%$ PHA-conditioned medium (6). Virus inoculation $(0 \mathrm{~h})$ was done in parallel for all cultures with $100 \mathrm{ng}$ of p24 per culture. The culture medium was completely exchanged $4 \mathrm{~h}$ after virus exposure and immediately before cell harvest of cells for the first time point $(6 \mathrm{~h})$. At all time points the cells were harvested and washed once in cold PBS. The cell pellets were then resuspended in 150 $\mu \mathrm{l} \mathrm{PCR}$ lysis buffer as described, vortexed briefly, and incubated at $37^{\circ} \mathrm{C}$ for $1 \mathrm{~h}$ with proteinase $\mathrm{K}$ as described (5). For PCR limiting dilution studies lysates from $3000,300,30,3$ cell equivalents of dendritic cells, $T$ cell and monocytes were used in parallel reactions. The conditioned medium is used as a source of lymphokine enriched medium to maintain cell viability $(6,8)$. Blocking with soluble CD4 10 $\mu \mathrm{g} / \mathrm{ml}$; (American Bio-Technologies, Cambridge, MA) was done as previously described $(9,10)$. $\left[{ }^{3} \mathrm{H}\right]$ Thymidine incorporation of 25,000 
cells was done overnight in flat bottom 96 well plates (Nunc) exposed to $1 \mu \mathrm{Ci}\left[{ }^{3} \mathrm{H}\right]$ thymidine/well (6).

Jurkat cell lines were obtained from the National Institutes of Health AIDS Research and Reference Reagent Repository. MT-2 and H9 cells were donated by Dr. W. Marshall. The IIIB viral strain of HIV-1 was obtained from culture supernatants of virus-infected Jurkat cell cultures at maximum syncytium formation. Titered virus stocks were stored at $-70^{\circ} \mathrm{C}$ in $50 \%$ fetal calf serum until use.

$R N A$ isolation and cDNA synthesis. Isolation of total RNA was according to Chomczynski and Sacchi (11). Generation of cDNA was done as described previously (12). First strand cDNA synthesis was primed using antisense primer: TGAGCAAGCTAACAGCAC (positions 8669-8652, antisense, see below) using Promega cDNA Synthesis System (Promega; Madison, WI) according to the instructions. The concentration of primer was $5 \times 10^{-6} \mathrm{M}$.

Polymerase chain reaction, primers, and probes. Oligonucleotide primers were synthesized on a synthesizer (Applied Biosystems, Inc., Foster City, CA). The primers were designed to detect early, intermediate, and late DNA species of the HIV reverse transcription process. With small modifications the position of primers corresponds to those used by Zack et al. (13). The primer sequences and nucleotide positions correspond to the convention in the HIV database of the HXB2 virus (Los Alamos National Laboratory, Los Alamos, NM). Primer pairs for detection of early (primers 1 and 2, Fig. 1) viral DNA: (“AA55): CTGCTAGAGATTTTCCACAC (positions 635-616, antisense) and ("M667"): CTAACTAGGGAACCCACTG (positions 498-516, sense). Intermediate (primers 4 and 5, Fig. 1) viral DNA synthesis: ("M666"): TGAGGGCTCGCCACTCCC (positions 417399, antisense). ("M665"): ACCCTGTGAGCCTGCATGG (positions 208-226, sense). Late (primers 1 and 3, Fig. 1 ) viral DNA synthesis: ("M661"): TCCTGCGTCGAGAGAGCTC (positions 693-675, antisense). ("M667," sense, see above). Primers to detect human $\beta$ globin (13) were ACACAACTGTGTTGTTCACTAGC (positions 117-136, sense) and CAACTTCATCCACGTTCACC (positions 226207, antisense).

Another set of primers were constructed to detect doubly spliced viral mRNA species: TGAGCAAGCTAACAGCAC (positions 86698652, antisense); AAGCGGAGACAGCGACGA (positions 59805997 , sense). Isolation and amplification of viral DNA was done as previously described (5). The cDNA reaction products were used for PCR following boiling for $2 \mathrm{~min}$.

An HIV-env specific oligonucleotide probe was end-labeled with ${ }^{32}$ P: GTCTGACTGTTCTGATGAGCTCTTCGTCGC (positions 6020-5090 antisense). An oligonucleotide probe was constructed to identify the specific $\beta$-globin amplification products: AAACAGACACCATGGTGCACCTGACTCC (positions 143-170, sense)(14). For detection of viral long terminal repeat (LTR) specific sequences two oligonucleotide probes were used: CTAGCAGTGGCGCCCGAACAGG, (positions 628-650, sense) and CAATAAAGCTTGCCTTGAGTGC (positions 526-547, sense).

Southern blotting and sequencing of PCR amplification products. Southern blotting was done according to standard procedures (15). Briefly, PCR fragments were separated on $12.5 \%$ polyacrylamide gels and visualized after ethidium bromide staining. The gels were soaked in $0.5 \mathrm{~N} \mathrm{NaOH} / 1.5 \mathrm{M} \mathrm{NaCl}$ for $15 \mathrm{~min}$, neutralized using $0.5 \mathrm{M}$ Tris pH 7.5/1.5 M NaCl, and electroblotted onto Gene Screen nylon membranes. Electro-transfer equipment ( Bio Rad Laboratories, Cambridge, MA) was used at $35 \mathrm{~mA}$ overnight in $2 \times$ Tris-buffered EDTA. Filters were UV illuminated, prehybridized, and hybridized as above except that formamide was replaced by $5 \%$ SDS in $\mathrm{H}_{2} \mathrm{O}$. Stringent wash for 28 mer oligonucleotides was $3 \times \mathrm{SSC}$ and $54^{\circ} \mathrm{C}$ and for shorter probes $(22$ mer) $3 \times$ SSC and $48^{\circ} \mathrm{C}$.

Two PCR products generated by primers for detection of late transcripts ("M667"/"M661") were excised separately from a low melting point $2.5 \%$ agarose gel and phenol/phenol/chloroform extracted, ethanol precipitated. The purified PCR products were sequenced with an automated DNA sequencer (737A; Applied Biosystems) using dye labeled dideoxyterminator.

\section{Results}

Formation of viral DNA in fractionated primary blood mononuclear cells. The conversion of viral RNA to DNA occurs in the cytoplasm of newly infected cells. Synthesis of the viral DNA depends on successful virus binding and entry. To determine the relative rate of conversion of viral RNA to DNA in purified primary blood mononuclear populations, nucleic acids were isolated from newly infected populations of blood-derived $\mathrm{T}$ helper dendritic cells, T cells, and monocytes infected with 100 ng of p24 equivalents of the IIIB strain of HIV-1. The presence of early, intermediate, and late products of DNA synthesis reactions were detected 6,18 , and $42 \mathrm{~h}$ after virus challenge using the PCR method adapted from that described by Zack and co-workers (13).

The three primer pairs used for this analysis are shown in Fig. 1. The primer pair ( 1 and 2 ) is used to detect early reverse transcribed DNA complementary to the U5 (U5/R) region of the viral RNA. The initial DNA fragment made is copied from the U5 and R sequences at the $5^{\prime}$ end of the viral RNA. The second primer pair (4 and 5) detects intermediate DNA complementary to the RNA U3 sequences. The late products were detected using a third primer pair ( 1 and 3 ) that amplifies sequences complementary to the viral RNA between the U5 region and the $5^{\prime}$ coding sequences (LTR/gag) of the viral RNA. DNA from this region is not made until the polymerase completes a copy of the entire viral RNA.

The experiment displayed in Fig. 2 and summarized in Table I shows that by ethidium bromide visualization early DNA transcripts appear by $6 \mathrm{~h}$ after infection of dendritic cell cultures. At this time evident early transcripts are weak or absent in infected $\mathrm{T}$ cells and monocyte cultures. The early transcripts are first strongly detected $18 \mathrm{~h}$ after infection in the $\mathrm{T}$ cell cultures. Little signal corresponding to DNA from this region is detectable in monocytes $42 \mathrm{~h}$ after infection.

Intermediate and late DNA transcripts can be detected in extracts of infected dendritic cells 18 and $42 \mathrm{~h}$ after infection, respectively. Intermediate DNA species do not appear in cultures of $\mathrm{T}$ cells until $42 \mathrm{~h}$ after infection and do not appear before $42 \mathrm{~h}$ in cultures of monocytes. Full-length transcripts are first detected in the infected dendritic cells by $42 \mathrm{~h}$ after

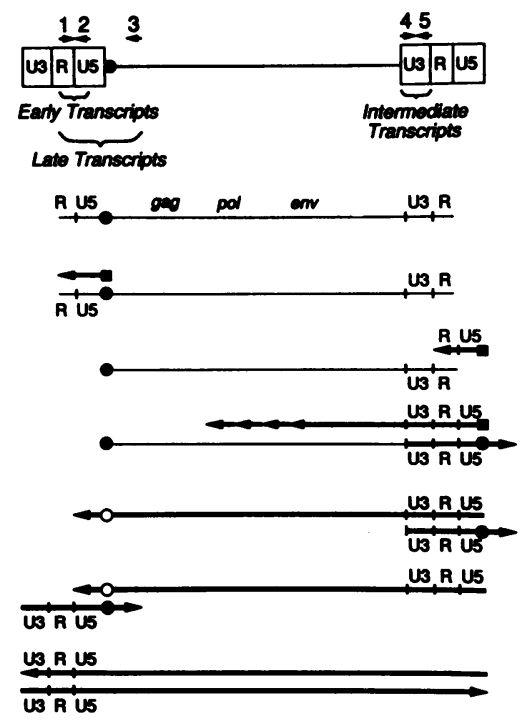

Figure 1. Schematic diagram of the process of conversion of the single-stranded RNA ( $t$ hin line) to a doublestranded DNA (thick lines) genome. The positioning of HIV-1 specific oligonucleotide primers for detection of early, intermediate, and late transcripts is shown (11). 


\section{Early Transcripts Intermediate Transcripts Complete Transcripts}
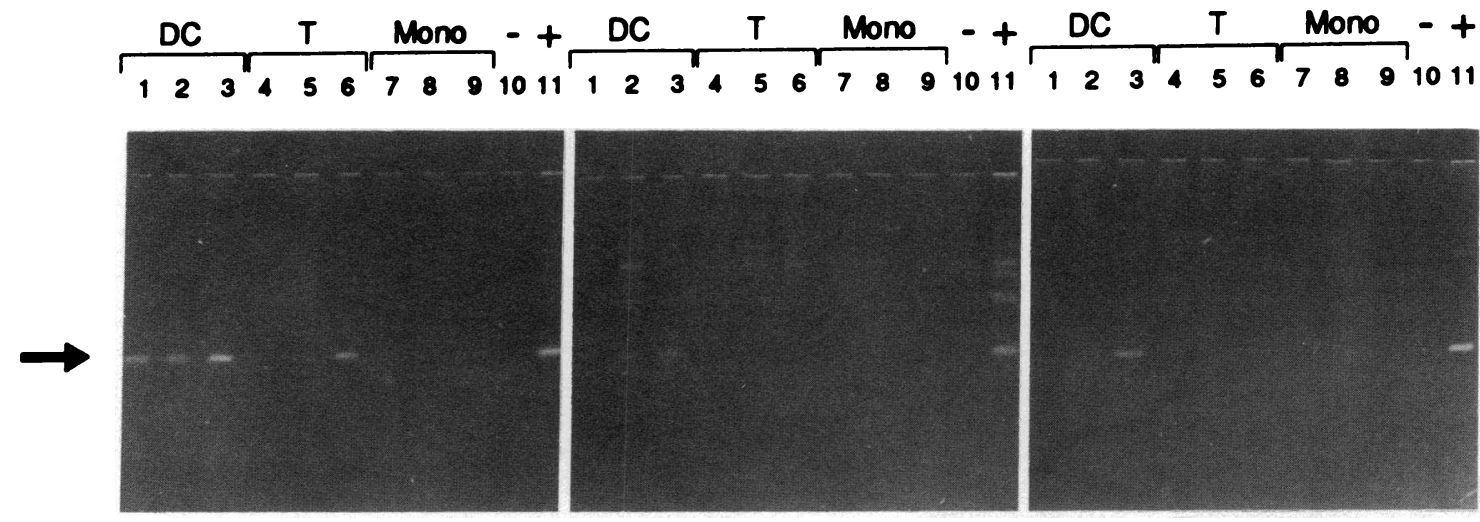

Figure 2. Detection of HIV-1 DNA in dendritic cells, T cells, and monocytes at $6 \mathrm{~h}$ (lanes 1, 4, 7), $18 \mathrm{~h}$ (lanes 2, 5, 8), and 42 h (lanes 3,6, 9). In one experiment the same DNA amount ( 300 cells) from primary T helper dendritic cells, T cells, and monocytes were subjected to 30 PCR amplification cycles using primers specific for R/U5 ( 1 and 2 ) for early transcripts ( $137 \mathrm{bp}$ ), U3 (4 and 5) for intermediate transcripts (209 bp), and LTR/gag ( 1 and 3 ) for complete transcripts ( $196 \mathrm{bp}$ ). The arrow indicates the predicted reaction products. A faint amplification product shorter than the $196 \mathrm{bp}$ complete transcript was detected. Both were sequenced, and the $196 \mathrm{bp}$ product was identical to the predicted amplification product. The faint shorter product contained sequences of nonspecific amplification products.

infection. Full-length DNA molecules present in extracts of monocytes are not detectable by $42 \mathrm{~h}$ after infection. The data shown are representative of two independent infection experiments done using different donor cells. PCR signals produced in extracts of SupT cells chronically infected with the IIIB isolate serve as controls in these experiments.

To obtain a more accurate comparison of the quantitative difference in the efficiency and rate of formation of viral DNA in the different cell types, we amplified PCR products in one set of experiments by limiting dilution of cell lysates of 3000,300 , 30 , and 3 cells of each of the three cell types. The experiment (not shown) confirms that early, intermediate, and late transcripts appear more rapidly in infected dendritic cell cultures at $1: 10$ ( 300 cell equivalents) and $1: 100$ ( 30 cell equivalents ) cell lysate dilution than is the case for infected $\mathrm{T}$ cell and monocyte cultures. At the highest dilution ( 3 cells) no products were amplified. This experiment was done twice with similar results.

In a second set of experiments the origin of the products amplified by the primer pair designed to detect full-length DNA transcripts was examined in more detail. For this analysis, extracts of infected dendritic cells, $T$ cells, and monocyte cell cultures were used 6,18 , and $42 \mathrm{~h}$ after infection. The DNA

Table I. Kinetics of HIV-1 Reverse Transcription in Primary Leukocytes

\begin{tabular}{clccc}
\hline & & $6 \mathrm{~h}$ & $18 \mathrm{~h}$ & $42 \mathrm{~h}$ \\
\hline Early & Dendritic cells & +++ & +++ & ++++ \\
transcripts & T cells & $(+)$ & ++ & +++ \\
& Monocytes & $(+)$ & $(+)$ & $(+)$ \\
Intermediate & Dendritic cells & + & +++ & +++ \\
transcripts & T cells & - & - & ++ \\
& Monocytes & - & - & - \\
Complete & Dendritic cells & - & ++ & ++++ \\
transcripts & T cells & - & + & ++ \\
& Monocytes & - & - & + \\
& & & & \\
\hline
\end{tabular}

in an aliquot of extract corresponding to 300 cells was incubated with the primer pair designed to detect full-length DNA transcripts. The products of the amplification reaction were transferred to nylon filters. Two radioactive oligonucleotide probes corresponding to the long terminal repeat region of the HXB2 provirus were used to detect these sequences (Fig. 3 ). Coamplification with primers for the $\beta$-globin gene was performed in the same reactions to normalize for variations in target DNA content. This reaction was probed using a radioactive DNA oligonucleotide complementary to the $\beta$-globin gene.

Fig. 3 shows that using a more sensitive Southern blotting technique, the HIV-1 DNA probe detects abundant PCR amplification products in extracts of the infected dendritic cell culture. The corresponding signals of the PCR amplifications of infected $T$ cells and monocytes are much weaker, but complete transcripts that were not visible by ethidium bromide staining (Fig. 2) can now be detected in $T$ cells at $18 \mathrm{~h}$ in monocytes at $42 \mathrm{~h}$. The signal corresponding to the amplified $\beta$-globin DNA is comparable in all the reactions. The experiment confirms that the PCR amplified products identified by ethidium bromide staining of the agarose gels correspond to the expected HIV-1 sequence. The experiments also demonstrate that full-length viral DNA is more abundant in infected dendritic cell cultures $48 \mathrm{~h}$ after infection than they are in infected $T$ cell and monocyte cultures when normalized for $\beta$-globin. The experiment was repeated five times with similar results. In one of those experiments the appearance of late transcripts was completely blocked in dendritic cells, Jurkat cells, and primary T cells by preincubation of the HIV-1 virus with $10 \mu \mathrm{g} / \mathrm{ml}$ soluble CD4 (American Bio-Technologies) before challenge (not shown). [ $\left.{ }^{3} \mathrm{H}\right]$ Thymidine incorporation at $24 \mathrm{~h} / 48 \mathrm{~h}$ of 25,000 dendritic cells was $1500 \mathrm{cpm} / 2900 \mathrm{cpm}$ compared with that of $25,000 \mathrm{H} 9$ cells $(145,000 \mathrm{cpm} / 241,000 \mathrm{cpm}), 25,000$ MT-2 cells $(187,000 \mathrm{cpm} / 242,000 \mathrm{cpm})$, or 25,000 Jurkat cells $(84,500 \mathrm{cpm} / \mathrm{ND})$.

The measurement of viral $m R N A$ in dendritic cells. To measure the onset of synthesis of new viral RNA in the infected cell cultures, an experiment was designed to detect spliced mRNA 


\section{Complete Transcripts}

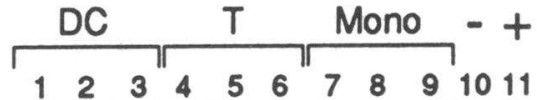

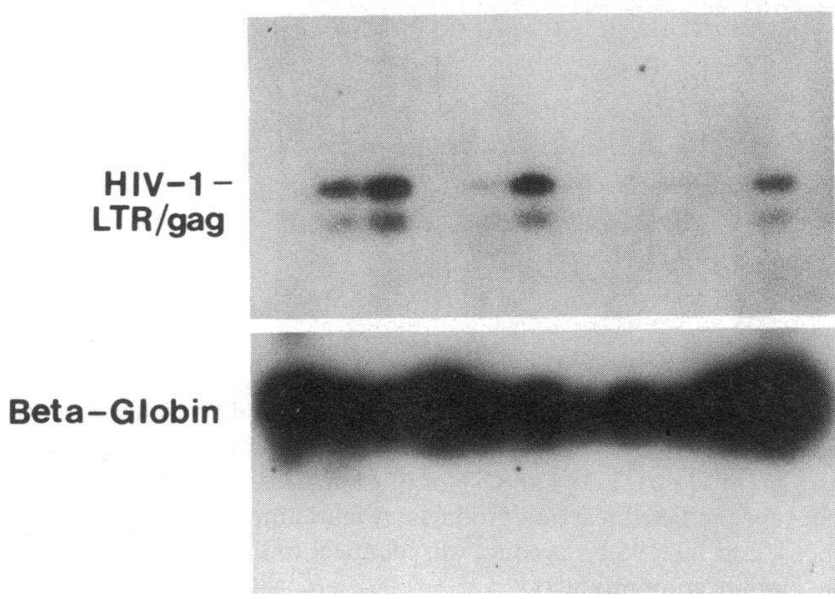

Figure 3. Southern blot of PCR amplified late transcripts (LTR/gag) coamplified with $\beta$-globin specific primers. Oligonucleotide probes for detection of viral and $\beta$-globin sequences are described in Methods.

transcripts. Several studies show that the first RNA products detected upon infection of $\mathrm{CD}^{+}{ }^{+} \mathrm{T}$ cells are multiply spliced mRNAs (16-18). For this reason RNA was purified from infected blood-derived $T$ cells, monocytes, and $T$ helper dendritic cell cultures 6,18 , and $42 \mathrm{~h}$ after infection. DNA complementary to the mRNA was made by using a DNA primer that recognizes a sequence in the nef region near the $3^{\prime}$ end of the viral RNA. All virus spliced HIV-1 mRNAs share a common 3' terminus that includes this sequence. The cDNA was amplified using a primer pair that flanks the major $5^{\prime}$ and $3^{\prime}$ splice sites within the $3^{\prime}$ half of the genome (Fig. 4). Use of this primer pair permits discrimination of signals produced by full-length virion RNA from those produced by spliced RNA products. The data of Fig. $5 A$ show that an amplified DNA product of the length predicted to be made from the spliced tat, rev, and nef mRNAs (357 nucleotides) is evident in RNA extracted from dendritic cells $18 \mathrm{~h}$ after infection. The identity of this DNA product was examined by Southern blotting after transfer of the DNA to a nylon filter and detected using a radioactive DNA probe complementary to the first exon of tat, rev, and $n e f$ (Fig. $5 B$, Table II). This experiment (Fig. $5 B$ ) shows that the amplified DNA product is of viral origin. No amplified product of this length was detected in RNA prepared from infected $T$ cells and monocytes $42 \mathrm{~h}$ after infection. A similar amplified
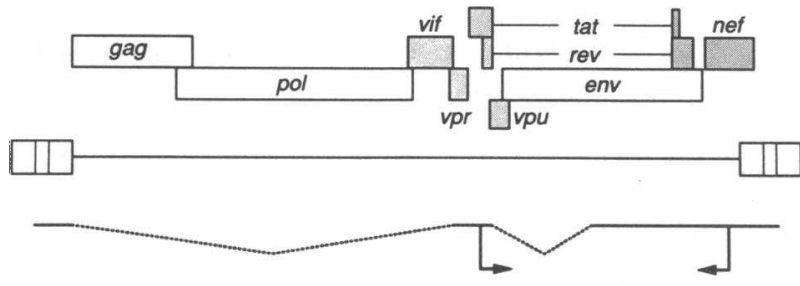

Figure 4. Position of primers for detection of spliced tat, rev, and nef HIV-1 mRNA products.
A
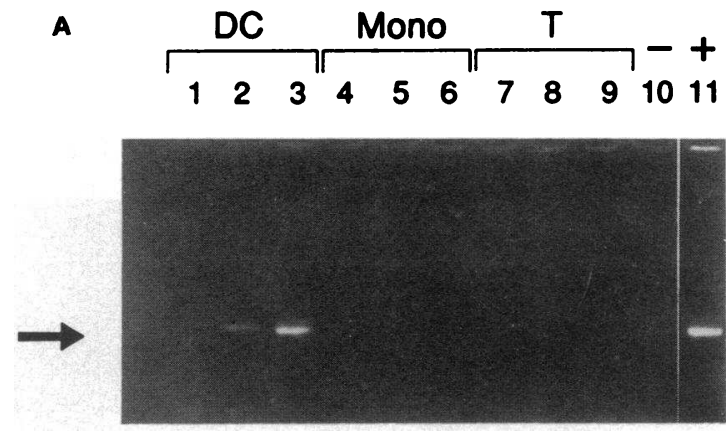

B
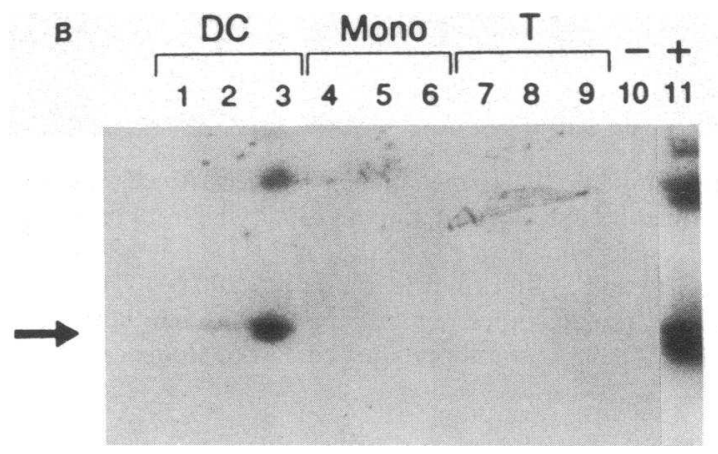

Figure 5. (A) Detection of spliced mRNA products for tat, rev, and $n e f$ in dendritic cells, monocytes, and T cells at $6 \mathrm{~h}$ (lanes $1,4,7)$, $18 \mathrm{~h}$ (lanes 2, 5, 8), and $42 \mathrm{~h}$ (lanes 3, 6, 9) specific PCR primers for spliced mRNAs. The ethidium bromide stained $2 \%$ agarose gel shows the predicted $357 \mathrm{bp}$ reaction products. cDNA from infected and uninfected Jurkat cells were used as controls. $(B)$ Detection of the amplified DNA products with a radioactive oligonucleotide probe (GTCTGACTGTTCTAATGAGCTCTTCGTCGC).

DNA product was detected when extracted RNA was reverse transcribed from SupT1 cells chronically infected with the IIIB strain of HIV-1.

\section{Discussion}

The experiments described here demonstrate the sensitivity of primary blood derived dendritic cell cultures to support replication of HIV-1. This can be attributed, at least in part, to the efficient uptake of virus particles and/or to early synthesis of the full-length viral DNA. The production of detectable amounts of early, intermediate, and late transcripts of viral DNA occurs much more rapidly in the dendritic cell cultures than it does in infected primary $T$ cells and monocytes. Use of the dendritic cell population at relatively low dilutions by limiting dilution minimizes possible contribution to the PCR signals obtained from a few contaminating $\mathrm{T}$ cells, monocytes, or $\mathrm{B}$ cells in the population. Additionally, primary B cells are not

Table II. Detection of Spliced mRNA Products for tat, rev, and nef in Primary Leukocytes

\begin{tabular}{llccc}
\hline & & $6 \mathrm{~h}$ & $18 \mathrm{~h}$ & $42 \mathrm{~h}$ \\
\hline All spliced & Dendritic cells & $(+)$ & ++ & ++++ \\
mRNA products & T cells & - & - & $(+)$ \\
of tat, rev, nef & Monocytes & - & - & - \\
\hline
\end{tabular}


reported to be productively infected by HIV-1 (19-22). The experiments also show that conversion of the viral RNA to DNA is more efficient and more rapid in primary $T$ cell populations than it is in primary monocytes. The delayed appearance of complete transcripts in monocytes as compared with those in $T$ cell cultures is consistent with recent reports (23). Though the IIIB strain in previous studies has been shown to infect monocytes (24) the high diversity of the biological properties by different strains of HIV-1 makes it possible that other strains may behave differently from the IIIB strain in this respect. In recent studies complete transcripts have been detected as early as $6 \mathrm{~h}$ after infection in 3-d PHA stimulated PBL cultures (25). In our experience and consistent with published studies (25) the kinetics of appearance of viral transcripts is much influenced by the prestimulation culture conditions. Thus, in our culture system complete viral transcription is significantly facilitated after 2-3 d of culture (not shown) as compared to overnight culture used in the present study.

There are two possible explanations for the observation that viral DNA transcripts appear more rapidly in dendritic cells than they do in $\mathrm{T}$ cells and monocytes. The process of virus particle binding and entry may be much more efficient for primary blood dendritic cells than it is for other cell types. If this is the case, the virus entry must be rapid and efficient despite the relatively low number of CD4 receptors present on the surface of the dendritic cells (3). The abundance of CD4 on the surface of the purified dendritic cell population is much lower than it is on the surface of $\mathrm{CD}^{+} \mathrm{T}$ cells. Postbinding events that facilitate virus entry must then be much more efficient in the purified dendritic cell population than in $\mathrm{CD}^{+} \mathrm{T}$ cells. Alternatively, the synthesis of viral DNA in the cytoplasm of the dendritic cell may be more efficient and more rapid than it is in other cells.

Recent studies have suggested that unstimulated blood dendritic cells are highly effective in supporting rapid viral uptake but have little or no capacity to support complete viral transcription but nevertheless transmit the infectious virus particles to surrounding $T$ cells (26). An alternative explanation of our observation would be that dendritic cells support efficient virus uptake but have a remarkable potential to boost HIV-1 production from a few contaminating cells even in the absence of DNA synthesis or cell division since irradiated cultures are productive (1). Our results (not shown) and other studies find in any case little or no viral replication as measured by protein or DNA in dendritic cells (26) or other primary cell isolates (25) cultured without an exogenous source of cytokines.

The early appearance of complete viral DNA transcripts and RNA products infected dendritic cell cultures is notable. Under the conditions used for these experiments, dendritic cell cultures do not incorporate significant amounts of thymidine (27). It is reported that complete reverse transcription fails to occur upon infection of resting populations of primary $\mathrm{T}$ cells (25). This observation notwithstanding, replication of retroviruses in nondividing cell populations has been observed previously (28). Replication of Rous sarcoma virus-induced cell transformation occurs without cell division in chick embryo cultures treated with cytosine arabinoside or vinblastine (29, 30 ). The visna retrovirus replicates well in nondividing populations of sheep choroid plexus cells (31), and HIV-1 replication occurs in gamma irradiated leukocytes $(1,19,28,32)$. Previous experiments with our dendritic cell cultures showed that HIV-1 replication continued following gamma irradiation doses that blocked host cell DNA replication and cell division (1). Preliminary experiments demonstrate that HIV-1 genomic integration occurs in cultures of blood dendritic cells as determined by Southern blotting (E. Langhoff, K. H. Kalland, W. A. Haseltine; not shown ). This is consistent with the emerging realization that lentiviral integration and replication is not dependent upon host cell DNA synthesis and cell division. Thus, HIV-1 productively infects monocytes and macrophages albeit less productively than primary $T$ cells (1). Very recently two studies have confirmed integration in nondividing monocytes and $G_{2}$ arrested HeLa cells $(28,32)$.

Spliced viral RNA products also appear earlier in infected primary $T$ helper dendritic cells than in infected primary $T$ cells and monocytes. The relatively early appearance of spliced mRNAs in the $T$ helper dendritic cell populations may also be a consequence of the increased efficiency of the early steps of the life cycle, including synthesis of the viral DNA. It is also possible that initiation of transcription of viral RNA is more efficient in primary dendritic cells than it is in most other cell types. Katajima et al. have recently observed in HIV-1 infected individuals preferential expression of $t a x / r$ ex mRNA of ( Human $T$ Lymphocyte Virus-1) attributed to non-T cell virus infection in articular lesions where dendritic cells are abundant (33). Macatonia et al. have observed $0.4-5.1 \%$ of blood dendritic cells from patients with tropical spastic paraparesis infected with Human T Lymphocyte Virus- 1 as determined by in situ hybridization (34).

It is observed that the HIV-1 promoter activity is strongest in the skin Langerhans cells in transgenic mice which carry the HIV-1 promoter integrated into the germ line (35). The skin Langerhans cells are thought to be closely related to the bloodderived $\mathrm{T}$ helper dendritic cells (36). The observation that primary blood dendritic cell cultures efficiently convert viral RNA to DNA upon exposure to virus and that subsequent steps of the virus life cycle are also supported as well as the observation that these cells are not killed by virus infection per se, raises the possibility that primary infections that result from exposure of mucus membranes to virus or virus infected cells results in initial infection of cells of the Langerhans/dendritic cell lineage. Infected Langerhans and dendritic cells may in turn serve as a source for infection of $T$ cells both in the blood and lymphatic system by uptake and transmission of virus but also serve as reservoirs for virus infection.

\section{Acknowledgments}

Cell lines MT-2 and H9 were provided by Dr. W. Marshall, DanaFarber Cancer Institute, Boston. We thank Jan Welch for work on the manuscript and Amy Emmerts for assistance with graphics.

E. Langhoff was supported by National Institutes of Health grant AI28734 and Friends of Dana-Farber. K. H. Kalland was supported by a General Cinema Fellowship and by the Norwegian Research Council for Science and Humanities. Additional support was from the Center for AIDS Research Grant P30A128691, Cancer Center Grant P30CA06516, and the Mathers Foundation.

\section{References}

1. Langhoff, E. 1991. Replication of human immunodeficiency virus type 1 in primary dendritic cells. Proc. Natl. Acad. Sci. USA. 88:7998-8002.

2. Knight, S. C., S. E. MaCatonia, and S. Patterson. 1990. HIV-1 infection of dendritic cells. Int. Rev. Immunol. 6:163-175.

3. Macatonia, S. E., R. Lau, S. Patterson, A. J. Pinching, and S. C. Knight. 
1990. Dendritic cell infection, depletion and dysfunction in HIV-infected individuals. Immunology. 71:18-45.

4. Poznansky, M. C., B. Walker, W. A. Haseltine, J. Sodroski, and E. Langhoff. 1991. A rapid method for quantitating the frequency of peripheral blood T cells containing HIV-1 DNA. J. Acquired Immune Defic. Syndr. 4:368-373.

5. Cameron, P. U., U. Forsum, H. Teppler, A. Granelli-Pipemo, and R. M. Steinman. 1992. During HIV-1 infection most blood dendritic cells are not productively infected and can induce allogeneic $\mathrm{CD}^{+} \mathrm{T}$ cells clonal expansion. Clin. Exp. Immunol. 88:226-236.

6. Langhoff, E., and R. M. Steinman. 1989. Clonal expansion of human T lymphocytes initiated by dendritic cells. J. Exp. Med. 169:315-320.

7. Freudenthal, P. S., and R. M. Steinman. 1990. The distinct surface of human blood dendritic cells, as observed after an improved isolation method. Proc. Natl. Acad. Sci. USA. 87:7598-7602.

8. Markowicz, S., and Engleman, E. G. 1990. Granulocyte-macrophage colony-stimulating factor promotes differentiation and survival of human peripheral blood dendritic cells in vitro. J. Clin. Invest. 85:955-961.

9. Clapham, P. R., J. N. Weber, D. Whitby, K. McIntosh, A. G. Dalgleish, P. J. Maddon, K. C. Deen, R. W. Sweet, and R. A. Weiss. 1989. Soluble CD4 blocks the infectivity of diverse strains of HIV and SIV for T cells and monocytes but not for brain and muscle cells. Nature (Lond.). 337:368-370.

10. Thali, M., U. Olshevsky, C. Furman, D. Gabuzda, J. Li, and J. Sodroski 1991. Effects of changes in gp120-CD4 binding affinity on human immunodeficiency virus type 1 envelope glycoprotein function and soluble CD4 sensitivity. $J$. Virol. 65:5007-5112.

11. Chomczynski, P., and N. Sacchi. 1987. Single-step method of RNA isolation by acid guanidinium thiocyanate-phenol-chloroform extraction. Anal. Biochem. 162:156-159.

12. Kalland, K. H., E. Langhoff, H. J. Bos, H. Gottlinger, and W. A. Haseltine. 1991. Rex-dependent nucleolar accumulation of HTLV-1 mRNA. New Biol. 3:389-397.

13. Zack, J. A., S. J. Arrigo, S. R. Weitsman, A. S. Go, A. Haislip, and I. S. Y. Chen. 1990. HIV-1 entry into quiescent primary lymphocytes: molecular analysis reveals a labile, latent viral structure. Cell. 61:213-222.

14. Lawn, R. M., A. Efstratiadus, C. O'Connell, and T. Maniatis. 1980. The nucleotide sequence of the human $\beta$-globin gene. Cell. 21:647-651.

15. Sambrook, J., E. F. Fritsch, and T. Maniatis. 1989. Molecular Cloning: A Laboratory Manual. 2nd ed. Cold Spring Harbor Laboratory, Cold Spring Harbor, NY. 931-957.

16. Kim, S., R. Byrn, J. Groopman, and D. Baltimore. 1989. Temporal aspects of DNA and RNA synthesis during human immunodeficiency virus infection: evidence for differential gene expression. J. Virol. 63:3708-3713.

17. Haseltine, W. A. 1991. Molecular biology of the human immunodeficiency virus type 1. FASEB (Fed. Am. Soc. Exp. Biol.). 5:2349-2360.

18. Arrigo, S. J., S. Weitsman, J. D. Rosenblatt, and I. S. Y. Chen. 1989. Analysis of rev gene function of human immunodeficiency virus type 1 replication in lymphoid cells by using quantitative polymerase chain reaction method. J. Virol. 63:4875-4881.

19. McDougal, J. S., A. Mawle, S. P. Cort, J. K. A. Nicholson, G. D. Cross, A Scheppler-Campbell, D. Hicks, and J. Sligh. 1985. Cellular tropism of the human retrovirus HTLV-III/LAV. I. role of T cell activation and expression of T4 antigen. J. Immunol. 135:3151-3162.
20. Montagnier, L., J. Gruest, S. Charmaret, C. Dauguet, C. Axler, D. Guetard, M. T. Nugeyre, F. Barre-Sinoussi, J. C. Chermant, J. B. Brunet, D. Klatzmann, and J. C. Gluckman. 1984. Adaptation of lymphadenopathy associated virus (LAV) to replication in EBV-transformed B lymphoblastoid cell lines. Science (Wash. DC). 226:63-66.

21. Barre-Sinoussi, F., J. C. Chermann, F. Rey, M. T. Nugeyre, S. Chamaret, J. Gruest, C. Dauguet, and C. Axler-Blin. 1983. Isolation of a T-lymphotropic retrovirus from a patient at risk for acquired immune deficiency syndrome (AIDS). Science (Wash. DC). 220:868-871.

22. Parmentier, H. K., D. van Wichen, D. M. D. S. Sie-Go, J. Goudsmit, J. C. C. Borleffs, and H-J. Schuurman. 1990. HIV-1 infection and virus production in follicular dendritic cells in lymph nodes. Am. J. Pathol. 137:247-251.

23. O'Brien, W. A., A. Namazie, S.-H. Mao, M. Mandegar, J. A. Zack, and I. S. Y. Chen. 1992. J. Cell. Biochem. Suppl. 16E:39.

24. Ho, D. D., T. R. Rota, and M. S. Hirsch. 1986. Infection of monocyte/ macrophages by human T lymphotropic virus type III. J. Clin. Invest. 77:17121715.

25. Zack, J. A., A. M. Haislip, K. Krogstad, and I. S. Y. Chen. 1992. Incompletely reverse-transcribed human immunodeficiency virus type 1 genomes in quiescent cells can function as intermediates in the retroviral life cycle. $J$. Virol. $66: 1717-1725$.

26. Cameron, P. U., P. S. Freudenthal, J. M. Barker, S. Gezelter, K. Inaba, and R. M. Steiman. 1992. Science (Wash. DC). 257:383-387.

27. Steinman, R. M., D. S. Lustig, and Z. A. Cohn. 1974. Identification of a novel cell type in peripheral lymphoid organs of mice. III. Functional properties in vivo. J. Exp. Med. 139:1431-1445.

28. Weinberg, J. B., T. J. Matthews, B. R. Cullen, and M. H. Malim. 1991 Productive human immunodeficiency virus type 1 (HIV-1) infection of nonproliferating human monocytes. J. Exp. Med. 174:1477-1482.

29. Bader, J. P. 1965. The requirement for DNA synthesis in the growth of Rous sarcoma and Rous associated viruses. Virology. 26:253-261.

30. Bader, J. P. 1973. Virus-induced transformation without cell division. Science (Wash. DC). 180:1068-1071.

31. Haase, A. T. 1986. Pathogenesis of lentivirus infections. Nature (Lond.) 322:130-136.

32. Lewis, P., M. Hensel, and M. Emerman. 1992. Human immunodeficiency virus infection of cells arrested in the cell cycle. EMBO (Eur. Mol. Biol. Organ.) J. 11:3053-3058.

33. Katajima, I., K. Yamamoto, K. Sato, Y. Nakajima, T. Nakajima, I. Maruyama, M. Osame, and K. Nishioka. 1991. Detection of human T cell lymphotropic virus type 1 proviral DNA and its gene expression in synovial cells in chronic inflammatory arthropathy. J. Clin. Invest. 88:1315-1322.

34. Macatonia, S. E., J. K. Cruickshank, P. Rudge, and S. C. Knight. 1992. Dendritic from patients with tropical spastic paraparesis are infected with HTLV 1 and stimulate autologous lymphocytes proliferation. AIDS Res. and Hum. Retro. 8:1699-1706.

35. Leonard, J., J. S. Khillan, H. E. Gendelman, A. Adachi, S. Lorenzo, H. Westphal, M. A. Martin, and M. S. Meltzer. 1989. The human immunodeficiency virus long terminal repeat is preferentially expressed in Langerhans cells in transgenic mice. AIDS Res. and Hum. Retroviruses. 5:421-430.

36. Larsen, C., R. Steinman, M. Witmer-Pack, D. Hankins, P. Morris, and J. Austyn. 1990. Skin migration and maturation of Langerhans cells in skin transplants and explants. J. Exp. Med. 172:1483-1493. 